\title{
SUBCLINICAL HYPOTHYROIDISM AND POLYCYSTIC OVARY SYNDROME
}

\author{
Zelija Velija-Asimi, Azra Burekovic, Amela Dizdarevic-Bostandzic \\ Clinical Centre University of Sarajevo, Bosnia and Herzegovina
}

Objectives:

The correlation of subclinical hypothyroidism (SH) and polycystic ovary syndrome (PCOS) is a still insufficiently explored entity. It is known that the patients with PCOS are at the greatest risk of infertility as well as cardiovascular morbidity and mortality. The aim of this study was to determine the existence of correlation between SH and PCOS. We also aimed to investigate the impact of SH on the metabolic and endocrine parameters in women with PCOS.

\section{Methods:}

The study included a total of one hundred and ninety-eight women of reproductive age with PCOS, divided into two groups: group I (83 patients with PCOS and SH) and group II (115 PCOS patients with normal thyroid function). Endocrine and metabolic parameters were measured in all patients and compared between women with and without elevated thyroid-stimulating hormone (TSH) levels. Laboratory tests were included lipid profile, glucose and insulin levels during oral glucose tolerance test, levels of C-reactive protein (CRP), steroids, prolactin and TSH. We also analysed insulin resistance index (HOMA-IR) and body mass index (BMI).

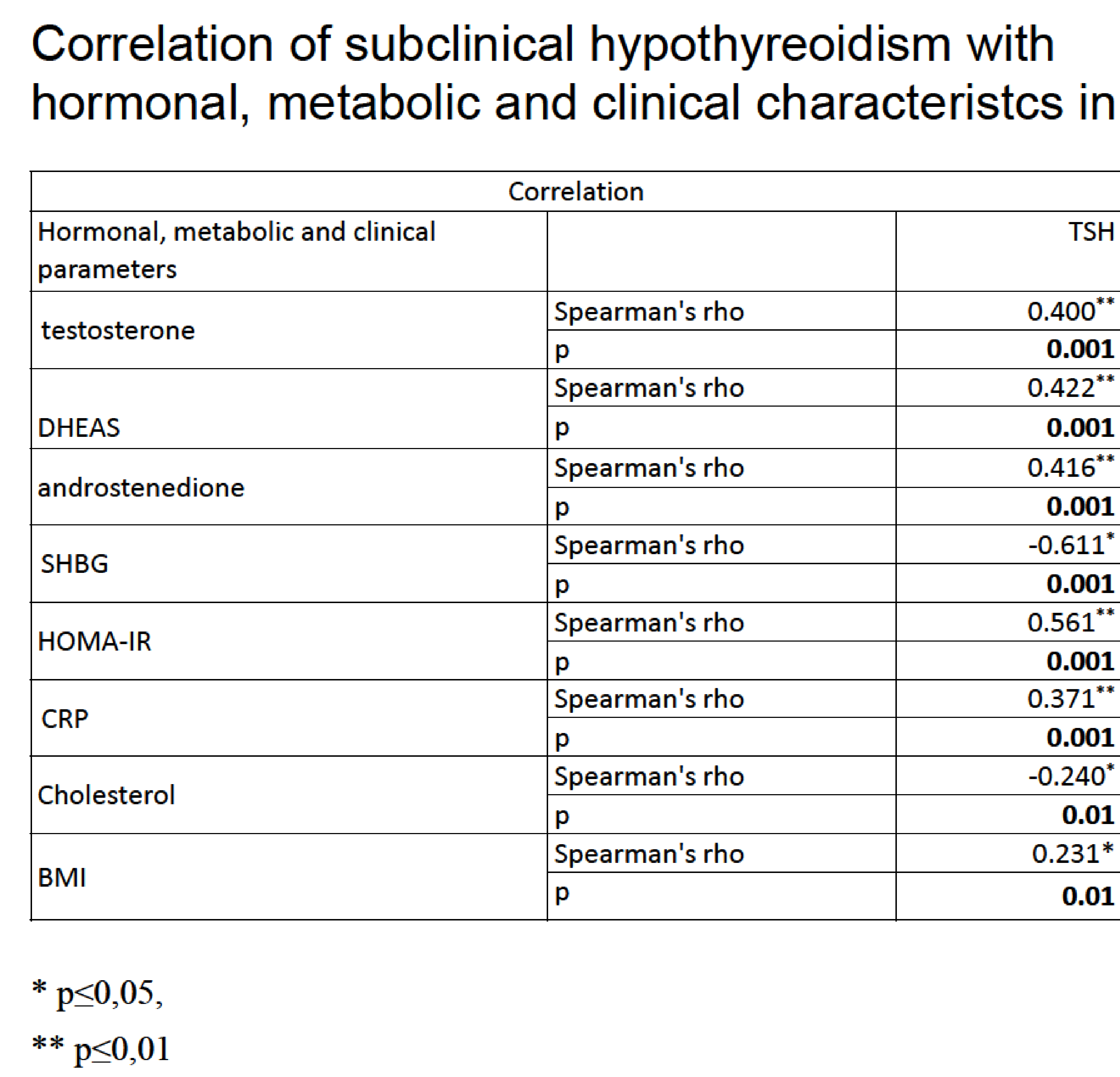

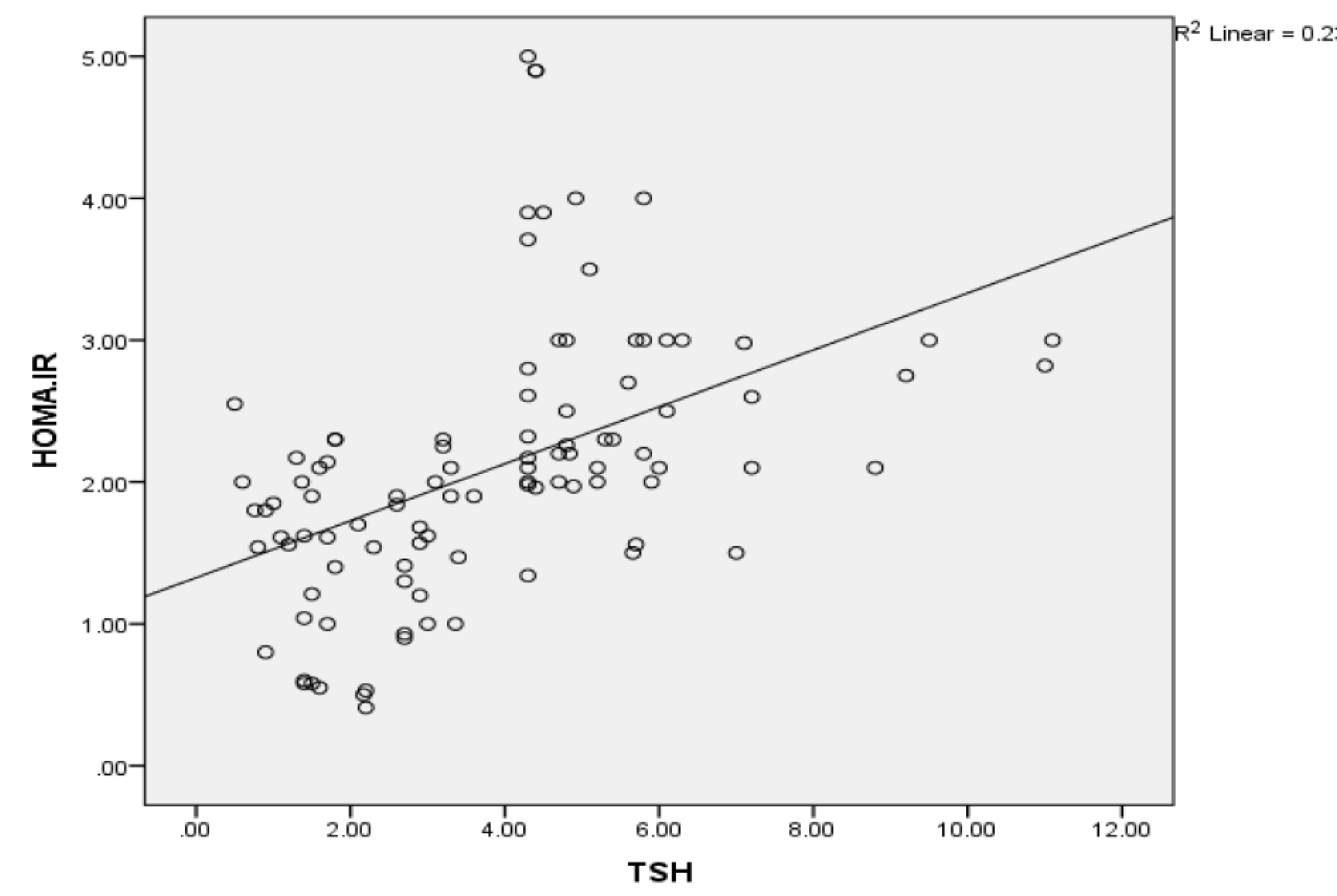

PCOS women with SH showed higher values of total cholesterol $(p=0.01)$, CRP $(p=0.001)$, HOMA-IR $(\mathrm{p}=0.001)$, androgens and BMI $(\mathrm{p}=0.01)$ compared to PCOS women with normal thyroid function. Furthermore, there was a significant correlation between subclinical hypothyroidism and metabolic, hormonal and clinical parameters in women with PCOS. SH is significantly correlated with: BMI $(\mathrm{p}=0.01)$, HOMA-IR $(\mathrm{p}=0.001)$, CRP $(\mathrm{p}=0.001)$, cholesterol $(\mathrm{p}=0.01)$ and with androgens $(\mathrm{p}=0.001)$. $\mathrm{SH}$ is negatively correlated with SHBG $(\mathrm{p}=0.001)$.

Conclusions:

Subclinical hypothyroidism significantly correlated with polycystic ovary syndrome. Subclinical hypothyroidism has a significant impact on clinical, metabolic and hormonal characteristics in patients with PCOS. Therefore, women with diagnosed PCOS should be screened for thyroid dysfunction.

\section{References:}

1.Trummer C, Schwetz V, Giuliani A, Obermayer-Pietsch B, Lerchbaum E. Impact of elevated thyroid-stimulating hormone levels in polycystic ovary syndrome. Gynecol Endocrinol. 2015 Oct;31(10):819-23. doi: 10.3109/09513590.2015.1062864.

2. Calvar CE, Bengolea SV, Deutsch SI, Hermes R, Ramos G, Loyato M. High frequency of thyroid abnormalities in polycystic ovary syndrome. Medicina (B Aires). 2015;75(4):213-7.

3. Huang R, Zheng J, Li S, Tao T, Liu W. Subclinical hypothyroidism in patients with polycystic ovary syndrome: distribution and its association with lipid profiles. Eur J Obstet Gynecol Reprod Biol. 2014 Jun;177:52-6. doi: 10.1016/j.ejogrb.2014.04.013 